\title{
Erratum to: Hereditary Angioedema Presenting with Recurrent Ascites
}

\author{
Rada Jesic $^{1} \cdot$ Djordje Culafic $^{1} \cdot$ Branka Bonaci-Nikolic $^{2}$
}

Published online: 14 November 2016

(C) Springer Science+Business Media New York 2016

\section{Erratum to: Dig Dis Sci (2005) 50:24-26 \\ DOI: $10.1007 / \mathrm{s} 10620-005-1272-2$}

Figure 1 of the above cited article was republished from the article "Ultrasonography in the diagnosis and monitoring of ascites in acute abdominal attacks of hereditary angioneurotic oedema", (European Journal of Gastroenterology \& Hepatology 2001 13(10):1225-1230), cited as reference 13 . We were recently informed that permission had not been granted for use of this figure in our publication.

This erratum is to certify that the publisher, Wolters Kluwer, has kindly granted retrospective permission for the publication of their figure in our Digestive Diseases and Sciences publication.

The online version of the original article can be found under doi: 10.1007/s10620-005-1272-2.

\footnotetext{
Djordje Culafic dculafic@EUnet.yu

1 Institute of Digestive Diseases, Clinic for Gastroenterology and Hepatology, Belgrade, Serbia

2 Institute of Allergy and Clinical Immunology, Clinical Center of Serbia, Belgrade, Serbia
} 